\title{
Alvin J Siteman Cancer Center
}

National Cancer Institute

\section{Source}

National Cancer Institute. A/vin / Siteman Cancer Center. NCI Thesaurus. Code C105620.

The Alvin J Siteman Cancer Center is dedicated to advancing new approaches to cancer prevention, diagnosis, and treatment through research. It became an $\mathrm{NCl}$-designated cancer center in 2001 and achieved Comprehensive Cancer Center status in 2004. Parent institutions include Barnes-Jewish Hospital and Washington University School of Medicine. Partner institutions include St. Louis Children's Hospital and BJC Healthcare. 